\title{
Zoonosis Due to Bruella suis with Special Reference to Infection in Dogs (Carnivores): A Brief Review
}

\author{
Moges Woldemeskel \\ Tifton Veterinary Diagnostic and Investigational Laboratory, Department of Pathology, \\ College of Veterinary Medicine, The University of Georgia, Tifton, USA \\ Email: mwoldem@uga.edu
}

Received March 27, 2013; revised April 27, 2013; accepted May 27, 2013

Copyright (C) 2013 Moges Woldemeskel. This is an open access article distributed under the Creative Commons Attribution License, which permits unrestricted use, distribution, and reproduction in any medium, provided the original work is properly cited.

\begin{abstract}
Brucella suis (B. suis) is the major cause of porcine brucellosis. Zoonosis due to B. suis infection associated with transmission by various animal species is reported. Recently an increase in brucellosis associated with feral swine transmitted $B$. suis infection in humans and hunting dogs is emerging. Reports on $B$. suis infection in carnivores including dogs is scant. This report gives a brief review of $B$. suis zoonosis with particular reference to B. suis infection in dogs (carnivores).
\end{abstract}

Keywords: Canine; Carnivores; Brucella suis; Review; Zoonosis

\section{Introduction}

Brucellosis is an infectious disease caused by bacteria belonging to genus Brucella, gram negative coccobacilli that infect various animal species and humans. Canine brucellosis is a worldwide disease of dogs mainly caused by Brucella canis (B. canis). B. canis is an important cause of reproductive failure, resulting in abortions in pregnant females, epididymitis and infertility in males. The disease is detrimental to the reproductive career of a breeding animal. B. canis is zoonotic, although the disease appears to be rare in humans. Other Brucella species occasionally associated with brucellosis in dogs include Brucella abortus, B. melitensis and B. suis. These infections occur occasionally when dogs ingest placentas from infected animals [1]. Among these, Brucella suis, which is the common cause of brucellosis in swine, poses a threat to human health as a zoonotic disease in most cases through exposure to infected swine or handling and consumption of infected pork. Published information on $B$. suis infection in dogs is scarce. Recent reports indicate its emerging occurrences in hunting dogs causing health hazards to humans in contact with infected dogs. This review article presents a brief account of $B$. suis zoonosis in general and canine associated infection in particular.

\section{Brucellosis: General}

Brucellosis is a chronic zoonotic disease resulting in un- dulant (undulating) fever in humans and abortion and infertility in animals [2]. It is one of the most important infectious causes of reproductive disorders in various species of animals. The disease is known under different names: contagious abortion, infectious abortion, and epizootic abortion. In horses, it is known as fistulous withers and poll evil. In cattle, the disease is called Bang's disease in recognition of a Danish veterinarian pioneer in the study of the disease in bovines. The disease in humans is called Melitococcosis, Malta fever, Mediterranean fever or Gibraltar fever following the name of the regions where it was first described. It is also known as undulating fever due to oscillating temperature presented by infected patients $[3,4]$.

Brucellosis is caused by bacteria of the genus Brucella, small, gram-negative bacilli or coccobacilli that prefer intracellular habitat. In animals, the organisms produce chronic infections with persistent or recurrent bacteremia manifested typically by abortion. Three classic species of Brucella were described originally based largely on the host of origin as B. melitensis B. abortus, and B. suis, in goats, cattle and swine, respectively. Currently, the species are defined based on their biochemical and serological reactions [5]. To this date, nine Brucella species are recognized. Seven of these including $B$. abortus (cattle), B. melitensis (sheep and goats), B. suis (pigs), $B$. ovis (sheep), B. canis (dogs), B. neotomae (wood rat), and B. microti (common vole, Microtusarvalis) affect 
terrestrial animals [6,7] while two others, B. ceti (dolphins) and B. pinnipedialis (seals) affect marine mammals [8]. The differences between the species are slight and quantitative rather than qualitative, and the number of biotypes within each species is large. This has led to the recommendation that all should be considered a single species, B. melitensis, and that the present species and variants with fixed properties be regarded as biotypes of the one species. However, most of the previous description and identification are still in use. Accordingly, the disease in cattle is caused by strains of $B$. abortus, the disease in sheep and goats by B. melitensis, and $B$. suis is found chiefly in swine. Cross infections do occur and almost all domestic species are susceptible [5]. For example B. abortus causes abortions, stillbirths, epididymitis, orchitis and sperm abnormalities in dogs [1].

Brucella organisms cause a zoonosis transmitted from their animal hosts to humans by direct contact with infected animals or, more often, through the consumption of raw animal products such as unpasteurized milk or cheese. Five of the known nine species of the genus Brucella are pathogenic for humans. This includes $B$. melitensis, B. abortus, B. suis, and B. canis transmitted to humans from sheep and goats, cattle and other bovidae, pigs and from dogs, respectively [9] and B. ceti from marine mammals [10].

\section{Brucella suis (B. suis)}

Brucella suis mainly infects pigs and is the main cause of porcine brucellosis $[4,11]$. It is an economically important cause of insurmountable reproductive loses in swine industry throughout the world [11]. It affects also other animals and humans leading to abortions and infertility in infected animals [2]. Swine brucellosis is infrequent and occurs sporadically in Europe, Asia, and Oceania [4]. The disease has never been reported from Finland, Norway, Great Britain, and Canada. Many predominantly Muslim countries and Israel are regarded free of B. suis infection due to religious beliefs that limited swine production [4]. Generally, although the disease is of widespread in occurrence globally, the prevalence is low with the exception of South America and South-East Asia, where the prevalence is higher [12]. In Latin America, swine brucellosis is enzootic and the region is thought to have the highest prevalence in the world. However, recent surveys of breeding operations in Argentina and Brazil have shown the percentage of infected herds to be low. The infection is possibly rooted in commercial farms where animals from different origins are brought together [4].

Brucella suis consists of five biovars, but the infection in pigs is caused by $B$. suis biovars 1,2 and 3 . The disease caused by biovars 1 and 3 is similar, while that caused by biovar 2 (Danish biovar) differs from 1 and 3 in its host range, its limited geographical distribution and its pathology. Different biovars play an important role in swine infection in different areas. In Latin America, infection with only biovar 1 , which predominates worldwide, has been confirmed, while both biovars 1 and 3 have been reported from the United States. Biovar 2 is found only in Europe and is limited to pigs and hares in central and Western Europe while biovar 3 is limited to the corn belt of the United States and to some areas of Asia and Africa. Infection with biovars 1 and 3 is spread directly or indirectly from pig to pig. In contrast, biovar 2 is transmitted to pigs when they feed on European hares (Lepus europaeus) [4]. In many European countries, the disease shows an epidemiological relationship to brucellosis caused by $B$. suis biovar 2 in hares. Through improved swine-breeding technology, swine have little access to hares and outbreaks have thus shown a marked decline [4]. In China, B. suis biovar 3 was introduced with breeding stock from Hong Kong in 1954 and spread rapidly through the southern part of the country [4]. Available literature and comparative studies indicate that the pathogenesis of $B$. suis biovars 1,2 and 3 is very similar. Differences are generally related to factors such as methods of exposure, infecting dose, age and breed of pigs and possibly minor differences between strains of the same biovar [13].

In many parts of the world, B. suis infection has become established in wild or feral pigs [11,12] complicating eradication efforts in domestic pigs [11]. Generally, serology in Italy, USA and Croatia has shown that approximately $20 \%$ - $30 \%$ of feral swine is Brucella positive. The high level of exposure suggests that there is an active transmission that may pose a serious threat to nearby domestic swine and hunters [2]. In USA, 18\% of feral pigs in South Carolina were serologically positive for $B$. suis. The serological results were further confirmed by isolation of $B$. suis biotype 1 from the lymph node of an affected feral pig. A trend of increasing incidence with age is noted suggesting that the pathogen is circulating among the population [14]. In Croatia [15] B. suis biovar 2 was isolated from $58 \%$ of swine and $62.5 \%$ of aborted piglets. It was further demonstrated that approximately $23 \%$ of wild boars examined were seropositive for Brucella sp. Wild boars therefore are considered as wildlife reservoirs of B. suis biovar 2 in Croatia. Approximately $10 \%$ of young adults and $28 \%$ of adult wild boars in open estates in southern Spain [16], 22\% of wild boar in Germany [17] and 7.5\% of 115 wild boars examined from four prefectures in Japan [18] were reported as seropositive for brucellosis. In wild boars of fenced estates in Spain, the incidence of seropositivity was approximately 32 and $38 \%$ in young adults and adults, respectively [16]. Incidence of $B$. suis in wild boar popula- 
tions has attained a very high level in southern Spain and pose a serious threat both to local domestic pigs, hunters and animal-care professionals [16].

\section{Brucella suis Infection in Non-Porcine Species}

\subsection{Brucella suis Infection in Various Domestic and Wild Animals}

Apart from its natural hosts, pigs, B. suis infection due to various biovars is reported in several non-natural host animal species. It is reported in cattle [12,19,20], dogs [12,21-23], horses [24] sheep [25], reindeer, caribou, hares and various murine species $[11,12,26]$ and humans [27]. Infections are transmitted through ingestion of contaminated materials or by co-habitation with infected animals. For example, Arctic foxes and wolves may contract $B$. suis biovar 4 [28], which causes serious disease in reindeer or caribou (Rangifer tarandus and its various subspecies), from infected reindeer throughout the Arctic region including Siberia, Canada and Alaska [29,30]. Some of the infected species of Rangifer tarandus are domesticated, others are wild and migratory [12]. The transmission and maintenance of rangiferine brucellosis due to $B$. suis are assumed to be similar to bovine brucellosis caused by Brucella abortus. It is thought that large numbers of Brucellae are disseminated into the environment at parturition, during which orally exposed animals become infected [31]. Group fawning over a short period of time under cool climatic conditions is optimal for transmission. Animals cohabiting range or utilizing reindeer or caribou as sources of food can be infected. Natural or experimental infection associated with rangiferine brucellosis has been described in wolves, bears, foxes, humans, a muskox, and various species of rodents [32-37]. The human cases reported were all from clinically ill native people utilizing caribou as part of their diet [38].

Strains of Brucella enzootic in various wild reservoir species (principally ruminants) are regularly transmitted to their predators [33]. Others animals including dogs, and rodents, such as rats and mice, may acquire other $B$. suis biovars by cohabitation with infected hosts. Cattle and horses may become infected by cohabitation or interaction with infected swine [28]. The infecting bacteria are invariably the well-defined biovars of the natural host species [11]. Wildlife species may be infected by $B$. suis or $B$. suis-like Brucella species [12]. Some variants of $B$. suis mainly affect caribou, reindeer or rodents, and are not important in pigs. Biovar 2, found only in Europe, is maintained in hares [11]. Murine brucellosis of the former Union of Soviet Socialist Republics (USSR), involves small rodents infected with $B$. suis biovar 5. Other similar situations have been reported from Queensland, Australia and from Kenya, in cases of which B. suis strains with different characteristics were involved, and at least one of them was difficult to classify [12].

\subsection{Brucella suis Infection in Dogs and Other Carnivores}

The main etiologic agent for brucellosis in dogs is $B$. canis, but sporadic cases of canine brucellosis caused by $B$. abortus, B. suis and B. melitensis have been reported [12]. Natural infection of dogs with Brucella suis is uncommon and only a few reports of such infection exist [21-23,33,39]. Dogs were first thought to be resistant to B. suis infection. However, it was later shown that dogs may be more easily infected and develop more severe clinical signs with $B$. suis infection than with $B$. canis, but that $B$. suis infection does not persist clinically. Various B. suis biotypes are isolated from naturally infected dogs. Brucella suis biotype 1 was repeatedly isolated from semen of a dog with clinical history of hind limb lameness associated with diskospondylitis of the lumbosacral joint with bone fracture, and epididymitis. The organism, however, could not be isolated from blood and urine of this dog [21]. One other previous report indicated isolation of $B$. suis identified to be similar to Brucella suis biotype 5 from a bitch [22]. B. suis biovar 5 causes also murine brucellosis [13]. Recently, an increase in B. suis detection in dogs in southern Georgia, USA, is reported. Nine out of 674 canine serum samples examined between June 2010 to July 2011 were positive for $B$. suis infection. Examination of case histories showed that all seropositive dogs had been recently exposed to feral swine during hunting expeditions, which led to a presumptive diagnosis of $B$. suis infection in the exposed dogs. All dogs were subsequently euthanized and testicles from two dogs (a hunting dog and a pet dog owned by a hog hunter) were subjected to Brucella culture. Culture of testicles from both animals showed a growth of Brucella sp., which was identified as B. suis by conventional biochemical testing and sequencing of the $16 \mathrm{~S}$ rRNA gene [39]. Biovar identification was not done.

Infection of predators (carnivores) by enzootic strains of Brucella present in prey species is common to many areas of the world. Antibodies against $B$. suis type 4, are reported in the serum of various domestic and wild Alaskan carnivores which feed on caribou (Rangifertarandusgranti), in Arctic Alaska. Sled dogs from five native villages on the range of the Arctic caribou herd are commonly infected. Although it is less common, the infection is reported in wolves (Canis lupus) and red fox (Vulpes fulva) [33] indicating that $B$. suis infection involves carnivores other than dogs exposed to infected wild animals. 


\section{Clinical Signs and Lesions Associated with B. suis Infection}

\subsection{Clinical Signs and Lesions in Swine}

The principal symptom of brucellosis in all animal species is abortion or premature expulsion of the fetus [4]. $B$. suis is the only recognized Brucella species that causes systemic or generalized infection leading to reproductive failure in pigs. Clinical manifestation of $B$. suis infection considerably varies in different herds [13] depending on the age of infected animal, previous exposure, and the organ involved [40]. The classical clinical manifestations are abortion, birth of weak piglets, infertility, orchitis, epididymitis, spondylitis (particularly of the lumbar and sacral regions), arthritis, paralysis of hind limbs, and lameness. Abortion may occur at any time during gestation and is influenced more by the time of exposure than by the time of gestation [13]. The rate of abortion is highest in sows or gilts infected via genital tract during mating [41]. Many infected herds may exhibit no clinical signs recognizable by the owners or the clinical signs may be transient. There is no pyrexia, and death is reported to be a rare occurrence [13].

The lesions in most cases are variably sized abscesses that frequently encompass different organs and tissues [4]. The disease in pigs caused by biovar 2, which appear to be non-pathogenic to humans, differs slightly from that caused by biovars 1 and 3 in that military brucellosis of the uterus is its feature [13]. Brucella suis biovar 4, causes similar lesions and clinical manifestations in reindeer and caribou (Rangifer tarandus sub spp.) as is caused by other Brucella species in pigs. It may cause fever, depression, abortion, retained placenta, metritis occasionally with blood-stained discharge, mastitis, bursitis, stillbirth, weak calves, orchitis, epididymitis, enlarged joints, lameness, and abscesses or granulomas in various locations including subcutaneous tissue, reproductive organs, and mammary gland [12,31]. Renal involvement has been described [42,43]. The frequency and duration of lesions and clinical signs under natural conditions are unknown [38]. Swine infected by other Brucella species is invariably asymptomatic and the infection remains as self-limiting localized infection of lymph nodes [13].

\subsection{Clinical Signs and Lesions in Dogs (Carnivores)}

No clinical signs are described as pathognomonic for canine brucellosis due to $B$. canis, although it is suspected as a cause of reproductive failure and infertility [44]. However, Brucellosis is an important rule-out for diskospondylitis in dogs [21]. Testicular degeneration and epididymitis are the common lesions of the disease in male dogs [5]. A granulomatous fibrosing epididymitis and prostatitis is reported in a dog infected with $B$. suis biotype 1 . The dog had a history of epididymitis that extended over 12 weeks. B. suis organisms were isolated from semen at 4 weeks, 8 weeks and 12 weeks after referral. Generally, dogs enter recovery phase by 4 to 6 weeks after infection, but the organisms persist in the lymphatic system. Dogs infected experimentally have a brief bacteremia, with primary localization of the organisms in the genital tract [21]. In experimentally infected Beagle with $B$. suis type 4 exposed through contaminated food or intra-peritoneal inoculation, Brucella organisms are distributed throughout the lymphatic system. The organisms may be present in kidneys and salivary glands and hence possibly in urine and saliva although not with sufficient regularity or intensity to commonly act as a source of infections. However, clinical signs of brucellosis were not observed in these dogs. Experimental infection of other canids (wolves) by B. suis type 4 present much the same general picture as seen in beagle dogs. Natural infection with Brucella suis type 4 in wolves on Alaskan and Siberian reindeer ranges is a significant cause of reproductive failure in wolves [32].

\section{Zoonotic Brucellosis (General)}

About five of the nine known Brucella species can infect humans [45]. Although there has been great progress in controlling the disease in many countries, there still remain regions where the infection persists in domestic animals and, consequently, transmission to human population frequently occurs [46]. Brucellosis, especially caused by Brucella melitensis, remains one of the most common zoonotic diseases worldwide with more than 500,000 human cases reported annually [45]. Recently, brucellosis has emerged as an important disease among Turkish immigrants in Germany [47].

The severity of human disease varies depending largely upon the infecting strain. The most pathogenic and invasive species with severe disease in humans is $B$. melitensis, followed in descending order by B. suis, B. abortus and $B$. canis $[4,48]$. Humans are relatively resistant to infection with Brucella canis and the disease is relatively mild compared with infection with other Brucella species [48]. The recently recognized Brucella species associated with marine animals may also have the capacity to cause human disease [46].

The prevalence of the infection in animal reservoirs provides a key to the occurrence of brucellosis in humans [4]. Of the three major host-specific species of Brucella (B. melitensis in goats, B. abortus, in cattle and B. suis, in swine), $B$. suis is considered the second most pathogenic species only slightly less virulent than $B$. melitensis to humans [2]. B. abortus and B. suis infections usually affect occupational groups, while B. melitensis infections occur more frequently than the other types in the general 
population. The greatest prevalence in man is found in countries with a high incidence of $B$. melitensis among goats, sheep, or both species [4].

$B$. melitensis, B. suis and B. abortus are listed as potential bio-weapons by the Centers for Disease Control and Prevention in the USA. This is due to the highly infectious nature of all three species, as they can be readily aerosolized and weaponized [11,49]. Moreover, an outbreak of brucellosis would be difficult to detect because the initial symptoms are easily confused with those of influenza [49].

Person-to-person transmission is not a significant problem except through blood or organ transfer which should be subject to proper control. Airborne or contact infection through environmental contamination may be a significant problem when infected animals are moved through densely populated areas, as is on the way to markets [46]. Most cases are the result of occupational exposure to infected animals [11]. This is particularly the case in industrialized countries and in those others in which food hygiene prevents foodborne brucellosis [46]. Some specific occupational groups including farm workers, veterinarians, ranchers, and meat-packing employees are considered at higher risk [50].

Brucellosis can be insidious and may present in many atypical forms. In many patients the symptoms are mild and, therefore, the diagnosis may not be even considered [46]. Furthermore, human brucellosis is known for complications and involvement of internal organs and its symptoms can be very diverse depending on the site of infection and may include encephalitis, meningitis, spondylitis, arthritis, endocarditis, orchitis, and prostatitis [4]. Common symptoms are undulant fever, malaise, insomnia, anorexia, headache, arthralgia, constipation, sexual impotence, nervousness and depression $[3,4]$.

\section{Zoonosis Due to B. suis}

Although transmission of $B$. suis from dogs to humans has not been reported, $B$. suis, as previously indicated, is second only to $B$. melitensis in its pathogenicity to humans [45]. B. suis has a much more restricted occurrence than B. melitensis and B. abortus. However, it is an important cause of human infection which can be as severe as that produced by $B$. melitensis [46]. The minimal infective dose of $B$. suis for humans is in the range of 10 100 colony forming units, and there are many cases of human infection owing to handling of infected feral and wild boars [16]. The sources and virulence of the organism vary with its biovar [46]. Biovar 2 which causes miliary brucellosis of the uterus in pigs [13] appears to be rarely pathogenic for humans [12,13] whereas biovars 1 and 3 are highly pathogenic to humans and cause severe disease $[12,46]$. B. suis biovar 4, a cause of Rangiferine brucellosis which apparently is not pathogenic for pigs [13] constitutes a serious zoonosis in Siberia, Alaska and Canada [12,13,46,51]. Naturally acquired human cases of biovar 5 infection have not been reported [46].

Brucellosis is almost invariably transmitted to people by direct or indirect contact with infected animals or their products [46]. For example among cases of human brucellosis in Germany, 59\% were related to the consumption of unpasteurized cheese from brucellosis-endemic countries and about $7 \%$ of the infections with a known source were laboratory acquired [47]. Transmission of the disease to humans in Arctic may be by direct contact or through consumption of milk and other inadequately cooked products from reindeer [12]. Most cases are due to $B$. suis 4 infection in native people as a result of their taste for raw caribou or bare-handed butchering and handling of freshly killed infected animals [32]. Bone marrow, which is considered to be a special delicacy in this region, is also among a source of human infection [12, 32]. However, it appears that $B$. suis 4 could be transmitted from infected dogs to humans under favorable circumstances via contamination by urine and saliva. Programs to prevent this disease in rural people who subsist on caribou or reindeer must take into account the remote possibility of infection via Brucella infected dogs [32].

Currently, swine-associated brucellosis in humans in the United States is predominantly associated with exposure to infected feral swine (wild hogs). Serologic surveys have detected endemic feral swine infection with B. suis in 10 states (Arkansas, California, Florida, Georgia, Hawaii, Louisiana, Mississippi, Missouri, South Carolina, and Texas). Two cases of brucellosis were reported in members of a hunt club who had killed and prepared meat from wild boars in South Carolina, USA [52]. In 2008, the state health departments in South Carolina and Pennsylvania reported two other cases of brucellosis apparently linked to feral swine hunts in Florida [53]. Of the 10 reported cases of brucellosis in 2008, seven were associated with wild pig hunting or preparation of wild pig meat. Feral hog data collected by United States Department of Agriculture (USDA) indicate seroprevalences as high as $50 \%$ in some feral swine herds in central Florida, and estimated the statewide prevalence to be $10 \%$ - $20 \%$. The most common species of Brucella isolated from Florida human patients is $B$. suis, which is endemic in Florida feral hogs [54]. A recent increase of $B$. suis infection in dogs in southern Georgia, USA, contracted from feral hogs cautions the public about the potential for transmission to humans in contact with infected hunting dogs and wild hogs [39].

Although B. canis is common in dogs, humans are relatively resistant to infection with Brucella canis and the disease is relatively mild compared with infection with other Brucella species [48]. The zoonotic risk of Brucella canis has been considered fairly high mainly for 
persons who handle breeding dogs in kennels or are exposed to infected animals. Transmission to humans in other circumstances has been thought to be rare. An uncommon outbreak of brucellosis caused by $B$. canis involving six people in a family (three children and three adults), a bitch and three puppies which had close daily contact with the family is reported [44].

\section{Diagnosis and Control}

Clinical examinations and clinical findings are inadequate for diagnosis of brucellosis. Isolation of the organism and serological tests are the only reliable ways to confirm a presumptive diagnosis [44]. In fact, isolation of the causative organism from fluids or tissues of suspected hosts is indisputable for definitive diagnosis of brucellosis [55]. Although bacteriological examination is often of great assistance in aiding a diagnosis, B. suis in the laboratory is extremely hazardous unless appropriate precautions are taken [13]. All in all, the genus Brucella belongs to Hazard Group II, and should be handled in a class I/III safety cabinet within Containment Level III accommodation by staff with adequate training and experience [13]. Apart from being hazardous, bacteriological isolation has some major drawbacks in that it is very time consuming, expensive, and not amenable to mass testing. Therefore, diagnosis is made by serological testing, usually of blood [55]. However, correct serological diagnosis may be confused unless vaccination is strictly controlled, used at the correct age with vaccine of sufficient quality and vaccinated animals are correctly identified [46].

B. abortus, B. melitensis, and B. suis infection in dogs can be diagnosed using the procedures described for cattle, except for ELISA, which has not been widely assessed in dogs. For $B$. canis infection the most reliable procedure is isolation of the organisms [46].

The currently emerging zoonotic potential of the disease due to canine associated brucellosis due to $B$. suis [40,52], and B. canis [44] and other Brucella species [47] warrants an increased public awareness for the control of the disease. Human brucellosis presents a great variety of clinical manifestations making it difficult to diagnose clinically. In some endemic areas case presenting with fever of unknown origin should be assumed to be due to brucellosis and the diagnosis must be ruled out or confirmed by laboratory tests [45]. Awareness of medical personnel for screening tests in susceptible patients such as children, immune-deficient individuals or pregnant women with fever of unknown origin, unexplained enlargement of spleen or liver or other systemic signs is necessary for proper treatment and diagnosis of brucellosis in humans [44]. Either failure to diagnose or delay in diagnosis is known to be among drawbacks in the diag- nosis and treatment of brucellosis. Brucellosis among Turkish immigrants in Germany is reported to be associated with major diagnostic delays, possibly resulting in treatment failures, relapses, chronic courses, complications, and a high case-fatality rate. Because of a lack of knowledge on the changing epidemiology of the disease, many physicians may not be able to act efficiently as first responders recognizing outbreaks [47].

There is general agreement that the most successful method for prevention and control of brucellosis in animals is through vaccination. While the ideal vaccine does not exist, in animals the attenuated strains of $B$. melitensis strain Rev.1 for sheep and goats and B. abortus strain 19 have proven to be superior to all others. The non-agglutinogenic B. abortus strain RB51 has been used in the USA and some Latin American countries, with encouraging results. Safe and effective vaccines for the prevention of human brucellosis are not generally available $[45,46]$. However, vaccination has played a significant role in the prevention of the disease in conjunction with other measures in the former USSR and China. Two live attenuated vaccine strains have been employed extensively in heavily infected areas [46].

Since brucellosis is zoonosis with a strong correlation between animal and human diseases, the ultimate source of human brucellosis is direct or indirect exposure to infected animals or their products. Therefore, prevention must be based on elimination of such contact. Eradication of the disease from animals is often beyond the financial and human resources of many developing countries necessitating supportive actions from various sectors, including those responsible for animal production, food safety, consumer education and health care [46]. Public health education and awareness and a setup of disease surveillance program especially in enzootic areas is needed to institute and coordinate brucellosis prevention program to alleviate and thereby avoid animal and human disease. The US and Cuba have successful national brucellosis eradication programs [4].

\section{Conclusion}

Brucellosis is currently regarded as a re-emerging zoonosis. Brucella suis is among the major cause of severe disease in human brucellosis and is considered to be the second most pathogenic species after $B$. melitensis. The major source of infection remains to be infected domestic or feral pigs. Due to the control programs in domestic swine production, the infection in feral swine and hunting dogs is emerging as an important source of B. suis infection to humans warranting an increased awareness by the general public, and veterinary as well as medical professionals. The authorities and health professionals involved in disease control programs should encompass 
feral swine and hunting dogs in the epidemiology of the disease and envision a concerted effort to control the infection in humans and animals.

\section{REFERENCES}

[1] Iowa State University, "Canine Brucellosis: Brucella canis, Contagious Abortion, Undulant Fever,” 2012. http://www.cfsph.iastate.edu/Factsheets/pdfs/brucellosis_ canis.pdf

[2] X. J. Meng, D. S. Lindsay and N. Sriranganathan, "Wild Boars as Sources for Infectious Diseases in Livestock and Humans," Philosophical Transactions of the Royal Society B, Vol. 364, No. 1530, 2009, pp. 2697-2707. doi:10.1098/rstb.2009.0086

[3] J. Megid, L. A. Mathias and C. A. Robles, "Clinical Manifestations of Brucellosis in Domestic Animals and Humans," The Open Veterinary Science Journal, Vol. 4, 2010, pp. 119-126.

[4] N. P. Acha and B. Szyfres, "Zoonoses and Communicable Diseases Common to Man and Animals,” 3rd Edition, Pan American Health Organization (PAHO), Washington DC, 2003.

[5] D. H. Schlafer and R. B. Miller, "Female Genital System. Pathology of the Gravid Uterus, Placenta and Fetus. Brucellosis,” In: M. G. Maxie, Ed., Jubb, Kennedy and Palmer's Pathology of Domestic Animals, 5th Edition, Saunders Elsevier, Philadelphia, 2007, pp. 484-489.

[6] H. C. Scholz, Z. Hubalek, I. Sedlacek, G. Vergnaud, H. Tomaso, S. Al Dahouk, F. Melzer, P. Kampfer, H. Neubauer, A. Cloeckaert, M. Maquart, M. S. Zygmunt, A. M. Whatmore, E. Falsen, P. Bahn, C. Gollner, M. Pfeffer, B. Huber, H. J. Busse and K. Nockler, "Brucella microti sp. nov., Isolated from the Common Vole Microtusarvalis," International Journal of Systematic and Evolutionary Microbiology, Vol. 58, No. 2, 2008, pp. 375-382.

[7] J. M. Verger, F. Grimont, P. A. Grimont and M. Grayon, “Taxonomy of the Genus Brucella," Annales de l'Institut Pasteur Microbiology, Vol. 138, No. 2, 1987, pp. 235238. doi:10.1016/0769-2609(87)90199-2

[8] G. Foster, B. S. Osterman, J. Godfroid, I. Jacques and A. Cloeckaert, "Brucella ceti sp. nov. and Brucella pinnipedialis sp. nov. for Brucella Strains with Cetaceans and Seals as Their Preferred Hosts," International Journal of Systematic and Evolutionary Microbiology, Vol. 57, No. 11, 2007, pp. 2688-2693. doi:10.1099/ijs.0.65269-0

[9] J. Godfroid, A. Cloeckaert, J. P. Liautard, S. Köhler, D. Fretin, K. Walravens, B. Garin-Bastuji and J. J. Letesson, "From the Discovery of the Malta Fever'S Agent to the Discovery of a Marine Mammal Reservoir, Brucellosis Has Continuously Been a Re-Emerging Zoonosis,” Veterinary Research, Vol. 36, No. 3, 2005, pp. 313-326. doi:10.1051/vetres:2005003

[10] A. H. Sohn, W. S. Probert, C. A. Glaser, N. Gupta, A. W. Bollen, J. D. Wong, E. M. Grace and W. C. McDonald, "Human Neurobrucellosis with Intracerebral Granuloma Caused by a Marine Mammal Brucella spp.,” Emerging Infectious Diseases, Vol. 9, No. 4, 2003, pp. 485-488. doi:10.3201/eid0904.020576
[11] Iowa State University, "Porcine and Rangiferine Brucellosis: Brucella suis, Enzootic Abortion, Contagious Abortion, Undulant Fever,” 2009.

http://www.cfsph.iastate.edu/Factsheets/pdfs/brucellosis_ suis.pdf

[12] OIE (Office International des Épizooties), "Porcine Brucellosis,” 2009.

http://www.oie.int/fileadmin/Home/eng/Health_standards /tahm/2.08.05_PORCINE_BRUC.pdf

[13] A. P. MackMillan, “Brucellosis,” In: B. Straw, S. D’Allaire, W. L. Mengeling and D. J. Taylor, Eds., Diseases of Swine, 8th Edition, Iowa State University Press, Ames, 1999, pp. 385-393.

[14] G. W. Wood, J. B. Hendricks and D. E. Goodman, "Brucellosis in Feral Swine,” Journal of Wilde Life Diseases, Vol. 12, No. 4, 1976, pp. 579-582.

[15] Z. Cvetnic, M. Mitak, M. Ocepek, M. Lojkic, S. Terzic, L. Jemersic, A. Humski, B. Habrun, B. Sostaric, N. Brstilo, B. Krt and B. Garin-Bastuji, "Wild Boars (Susscrofa) as Reservoirs of Brucella suis Biovar 2 in Croatia," Acta Veterinaria Hungarica, Vol. 51, No. 4, 2003, pp. 465-473. doi:10.1556/AVet.51.2003.4.4

[16] F. Ruiz-Fons, J. Vicente, V. Vidal, U. Höfle, D. Villanúa, C. Gauss, J. Segalés, S. Almería, V. Montoro and C. Gortázar, "Seroprevalence of Six Reproductive Pathogens in European Wild Boar (Susscrofa) from Spain: The Effect on Wild Boar Female Reproductive Performance," Theriogenology, Vol. 65, No. 4, 2006, pp. 731-743.

[17] S. Al Dahouk, K. Nöckler, H. Tomaso, W. D. Splettstoesser, G. Jungersen, U. Riber, T. Petry, D. Hoffmann, H. C. Scholz, A. Hensel and H. Neubauer, "Seroprevalence of Brucellosis, Tularemia, and Yersiniosis in Wild Boars (Susscrofa) from North-Eastern Germany," Journal of Veterinary Medicine Series B-infectious Diseases and Veterinary Public Health, Vol. 52, No. 10, 2005, pp. 444455.

[18] M. Watarai, N. Ito, Y. Omata and N. Ishiguro, “A SeroLogical Survey of Brucella spp. in Free-Ranging Wild Boar (Susscrofaleucomystax) in Shikoku, Japan,” Journal of Veterinary Medical Science, Vol. 68, No. 10, 2006, pp. 1139-1141. doi:10.1292/jvms.68.1139

[19] D. R. Cook and J. W. Noblem, "Isolation of Brucella suis from Cattle,” Australian Veterinary Journal, Vol. 61, No. 8, 1984, pp. 263-264. doi:10.1111/j.1751-0813.1984.tb15539.x

[20] D. R. Ewalt, J. B. Payeur, J. C. Rhyan and P. L. Geer, "Brucella Suisbiovar 1 in Naturally Infected Cattle: A Bacteriological, Serological and Historical Study,” Journal of Veterinary Diagnostic Investigation, Vol. 9, No. 4, 1997, pp. 417-420. doi:10.1177/104063879700900414

[21] S. C. Barr, B. E. Eilts, A. F. Roy and R. Miller, "Brucella suis Biotype 1 Infection in a Dog," Journal of the American Veterinary Medical Association, Vol. 189, No. 6, 1986, pp. 686-687.

[22] J. M. Verger, M. Gâté, M. Piéchaud, R. Chatelain, J. Ramisse and J. Blancou, “Isolation of 'Brucella suis' Biotype 5 from a Bitch, in Madagascar. Validity of the SpeCies Name 'Brucella canis',' Annals of Microbiology (Paris), Vol. 126, No. 1, 1975, pp. 57-74. 
[23] E. Hellmann and H. U. Sprenger, "Brucella suis Infection in the Dog," Berliner und Münchenertierärztliche-Wochenschrift, Vol. 91, No. 19, 1978, pp. 385-387.

[24] M. A. Portugal, A. Nesti, W. Giorgi, E. N. Franca and B. S. de Oliveira, "Brucellosis in Equines Caused by Brucella suis," Arquivos do InstitutoBiológico (S. Paulo), Vol. 38, No. 3, 1971, pp. 125-132.

[25] F. A. Paolicchi, H. R. Terzolo and C. M. Campero, "Isolation of Brucella suis from the Semen of a Ram," The Veterinary Record, Vol. 132, No. 3, 1993, p. 67. doi:10.1136/vr.132.3.67

[26] K. A. Neiland, J. A. King, B. E. Huntley and R. O. Skoog, "The Diseases and Parasites of Alaskan Wildlife Populations, Part I Some Observations on Brucellosis in Caribou,” Journal of Wild Life Diseases, Vol. 4, No. 2, 1968, pp. 27-36.

[27] N. E. Lucero, G. I. Escobar, S. M. Ayala, P. Silva Paulo and K. Nielsen, "Fluorescence Polarization Assay for Diagnosis of Human Brucellosis," Journal of Medical Microbiology, Vol. 52, No. 10, 2003, pp. 883-887. doi:10.1099/jmm.0.05217-0

[28] Z. Cvetnic, S. Spicis, S. Curic, B. Jukic, M. Lojkic, D. Albert, M. Thiébaud and B. Garin-Bastuji, "Isolation of Brucella suis Biovar 3 from Horses in Croatia," The Veterinary Record, Vol. 156, No. 18, 2005, pp. 584-585.

[29] G. Jungersen, V. Sørensen, S. B. Giese, J. A. Stack and U. Riber, "Differentiation between Serological Responses to Brucella suis and Yersinia enterocolitica O:9 after Natural or Experimental Infection in Pigs,” Epidemiology and Infection, Vol. 134, No. 2, 2006, pp. 347-357. doi:10.1017/S095026880500511X

[30] E. S. Orlow, "Brucellosis in Reindeer," Proceedings of the 17th World Veterinary Congress, Hanover, 14-21 August 1963, pp. 585-588.

[31] R. A. Dieterich, "Brucellosis,” In: R. A. Dieterich, Ed., Alaskan Wildlife Diseases, Institute of Arctic Biology, Fairbanks, 1981, pp. 53-58.

[32] K. A. Neiland and L. G. Miller, "Experimental Brucella suis Type 4 Infections in Domestic and Wild Alaskan Carnivores," Journal of Wild Life Diseases, Vol. 17, No. 2, 1981, pp. 183-189.

[33] K. A. Neiland, "Further Observations on Rangiferine Brucellosis in Alaskan Carnivores," Journal of Wildlife Diseases, Vol. 11, No. 1, 1975, pp. 45-53.

[34] C. C. Gates, G. Wobeser and L. B. Forbes, "Rangiferine Brucellosis in a Muskox, Ovibosmoschatusmoschatus (Zimmermann)," Journal of Wildlife Diseases, Vol. 20, No. 3, 1984, pp. 233-234.

[35] K. A. Neiland, "Rangiferine Brucellosis in Alaskan Canids," Journal of Wildlife Diseases, Vol. 6, No. 3, 1970, pp. 136-139.

[36] L. G. Miller and K. A. Neiland, "Experimental Infections by Brucella suis Type 4 in Alaskan Rodents," Journal of Wild Life Diseases, Vol. 16, No. 4, 1980, pp. 457-464.

[37] M. E. Meyer, "Identification and Virulence Studies of Brucella Strains Isolated from Eskimos and Reindeer in Alaska, Canada, and Russia,” American Journal of Veterinary Research, Vol. 27, No. 116, 1966, pp. 353-358.
[38] B. Lorry and B. Forbes, "Isolates of Brucella suis Biovar 4 from Animals and Humans in Canada, 1982-1990," Canadian Veterinary Journal, Vol. 32, No. 11, 1991, pp. 686-688.

[39] S. Ramamoorthy, M. Woldemeskel, A. Ligett, R. Snider, R. Cobb and S. I. Rajeev, "Brucella suis Infection in Dogs, Georgia, USA,” Letter, Emerging Infectious Diseases, Vol. 17, No. 12, 2011, pp. 2386-2387. doi:10.3201/eid1712.111127

[40] J. H. Gillespie and I. F. Timoney, "Hagan and Bruner’s Infectious Diseases of Domestic Animals," Cornell University Press, Ithaca, 1981.

[41] B. Deyoe and C. A. Manthei, "Swine Brucellosis," Proceeding, Symposium on Factors Producing Embryonic and Fetal Abnormalities, Death, and Abortion in Swine, Chicago, 2-3 October 1967, pp. 54-60.

[42] S. V. Tessaro and L. B. Forbes, "B. suis Biotype 4: A Case of Granulomatous Nephritis in a Barren Ground Caribou (Rangifer Tarandus Groenlandicus L.) with a Review of the Distribution of Rangiferine Brucellosis in Canada,” Journal of Wild Life Disease, Vol. 22, No. 4, 1986, pp. 479-483.

[43] R. A. Dieterich, B. L. Deyoe and M. S. Morton, "Effects of Killed Brucella abortus Strain 45/20 Vaccine on Reindeer Later Challenge Exposed with Brucella suis Type 4," American Journal of Veterinary Research, Vol. 42, 1981, pp. 131-134.

[44] N. E. Lucero, R. Corazza, M. N. Almuzara, E. Reynes, G. I. Escobar, E. Boeri and S. M. Ayala, "Human Brucella canis Outbreak Linked to Infection in Dogs,” Epidemiology and Infection, Vol. 138, No. 2, 2009, pp. 280-285.

[45] M. N. Seleem, S. M. Boyle and N. Sriranganathan, "Brucellosis: A Re-Emerging Zoonosis,” Veterinary Microbiology, Vol. 140, No. 3-4, 2010, pp. 392-398. doi:10.1016/j.vetmic.2009.06.021

[46] WHO (World Health Organization), "Brucellosis in Animals and Humans,” WHO, Geneva, 2006.

[47] S. A. Dahouk, H. Neubauer, A. Hensel, I. Schoneberg, K. Nockler, K. Alpers, H. Merzenich, K. Stark and A. Jansen, "Changing Epidemiology of Human Brucellosis, Germany, 1962-2005,” Emerging Infectious Disease, Vol. 13, No. 12, 2007, pp. 1895-1900.

[48] K. Hartmann and C. E. Greene, "Disease Caused by Systemic Bacterial Infection. Brucellosis,” In: S. J. Ettinger and E. C. Feldman, Eds., Text Book of Veterinary Internal Medicine. Disease of the Dog and Cat, 6th Edition, Elsevier Saunders, St. Louis Missouri, 2005, pp. 625-628.

[49] P. S. Chain, D. J. Comerci, M. E. Tolmasky, F. W. Larimer, S. A. Malfatti, L. M. Vergez, F. Aguero, M. L. Land, R. A. Ugalde and E. Garcia, "Whole-Genome Analyses of Speciation Events in Pathogenic Brucellae," Infection and Immunity, Vol. 73, No. 12, 2005, pp. 83538361. doi:10.1128/IAI.73.12.8353-8361.2005

[50] F. Tabak, E. Hakko, B. Mete, R. Ozaras, A. Mert and R. Ozturk, "Is Family Screening Necessary in Brucellosis?" Infection, Vol. 36, No. 6, 2008, pp. 575-577. doi:10.1007/s15010-008-7022-6

[51] L. B. Forbes, "Isolates of B. suis Biotype 4 from Animals 
and Humans in Canada, 1982-1990," Canadian Veterinary Journal, Vol. 32, No. 11, 1991, pp. 686-688.

[52] C. T. Starnes, R. Talwani, J. A. Horvath, W. A. Duffus, and C. S. Bryan, "Brucellosis in Two Hunt Club Members in South Carolina," Journal of South Carolina Medical Association, Vol. 100, No. 4, 2004, pp. 113-115.

[53] CDC (Center for Disease Control and Prevention), "Brucella suis Infection Associated with Feral Swine Hunting in Three States, 2007-2008," Morbidity and Mortality Weekly Report, Vol. 58, No. 22, 2009, pp. 618-621.

http://www.cdc.gov/mmwr/preview/mmwrhtml/mm5822 a3.htm
[54] FDH (Florida Department of Health), "Florida Zoonotic Disease Surveillance Program-Brucellosis,” 2012. http://myfloridaeh.com/medicine/arboviral/Zoonoses/Zoo notic-brucellosis.html

[55] K. Nielsen, P. Smith, W. Yu, P. Nicoletti, P. Elzer, C. Robles, R. Bermudez, T. Renteria, F. Moreno, A. Ruiz, C. Massengill, Q. Muenks, G. Jurgersen, T. Tollersrud, L. Samartino, S. Conde, L. Forbes, D. Gall, B. Perez, X. Rojas and A. Minas, "Towards Single Screening Tests for Brucellosis," Revue Scientifique et Technique-Office International des Epizooties, Vol. 24, No. 3, 2005, pp. 10271038. 